\title{
Quantitative Electron Tomography of Size-controlled Metallic Nanodots on Sintered Titania Photocatalysts
}

\author{
K. Yoshida, ${ }^{* * *}$ P.L. Gai, ${ }^{* *}$ S. Sueda, ${ }^{* * *}$ N. Tanaka****
}

* Nanostructures Research Laboratory, Japan Fine Ceramics Center, Nagoya, 456-8587, Japan

** The Nanocentre, Department of Chemistry, Department of Physics and Department of Electronics, The University of York, York Y010 5DD, U.K.

*** Department of Crystalline Materials Science, Ecotopia Science Institute, Nagoya University, Furo-cho, Chikusa-ku, Nagoya, 464-8603, Japan

Page Gold $(\mathrm{Au})$ and silver $(\mathrm{Ag})$ nanoparticles supported on titanium dioxide $\left(\mathrm{TiO}_{2}\right)$ are characterized using the Z-contrast of high-angle annular dark-field scanning transmission electron microscopy (HAADF-STEM), and the 3D morphologies of $\mathrm{Au}$ and $\mathrm{Ag}$ on $\mathrm{TiO}_{2}$ catalysts are carefully quantified by developed measurement programs. The $\mathrm{Au}$ and $\mathrm{Ag}$ nanoparticles on $\mathrm{TiO}_{2}$ are well known as high active oxidation catalysts, and much $3 \mathrm{D}$ research of these $\mathrm{TiO}_{2}$ catalysts has been reported [1-3]. HAADF-STEM tomography has proven to be a quite effective tool for analyzing such catalytic nanomaterials [4,5]. This study is also interested in the high contrast imaging of HAADF-STEM.

In contrast, the convergent electron beam of HAADF-STEM sometimes damages samples. This effect can be an especially serious problem in tomography, because a lengthy observation is required in order to obtain tilt series for 3D reconstruction. In fact, degradation of 3D reconstructed data was a concern because of the diffusion and coalescence of metallic nanoparticles on oxide support or the destruction of the $\mathrm{TiO}_{2}$ support [6]. In the present study, a cryogenic technique, which has been commonly used in electron tomography for biological samples, was employed in order to avoid such irradiation damage. The metallic nanoparticles and $\mathrm{TiO}_{2}$ support were quite stable under the cryogenic conditions at $78 \mathrm{~K}$ even when electron irradiation was performed for 3 or more hours. The present results clearly indicate that the cryogenic system is advantageous for electron tomography of inorganic materials.

FIG.1(a) is a slice image of the 3D reconstructed image, and FIG.1(b) is a histogram of the intensity distribution in the slice. This histogram shows that there are four types of peaks, which are larger than the case of $\mathrm{Au} / \mathrm{TiO}_{2}$. This means that two different types of metallic nanoparticles were supported on $\mathrm{TiO}_{2}$. Threshold values are determined in order to distinguish such different types of nanoparticles. The first threshold value [a] between $\mathrm{Au}$ and $\mathrm{Ag}$ was determined as a value that gives the deepest valley in intensity distribution between the peak near 160 and the other near 100 [arbitrary units]. Next, the second threshold value [b] between $\mathrm{Au}$ and $\mathrm{TiO}_{2}$ and threshold value [c] between $\mathrm{TiO}_{2}$ and vacuum were similarly determined as values that give the deepest valley between each peak in the histogram.

All nanoparticles have intensity gradients from the centre to the edge; the intensity of the Au edge overlaps the intensity of the Ag centre. However, the intensity of the Au centre is different from the intensity of the $\mathrm{Ag}$ centre; therefore, the maximum intensity of each nanoparticle is very important for distinguishing $\mathrm{Au}$ from Ag. When the maximum intensity of one nanoparticle exceeds the threshold value [a], the surrounding voxels whose intensities are over the threshold value $[c]$ were coded as a light grey colour for Au. In the same way, Ag nanoparticles were coded as a light grey 
colour by measuring their maximum intensities. A color-coded tomogram of $\mathrm{Au} / \mathrm{Ag} / \mathrm{TiO}_{2}$ is shown in FIG.1(c). The present electron tomography visualized the heterogeneous diffusion of photoexcited electrons dominating a reduction process in the photocatalysis. We can see Au nanoparticles, which surround a previously deposited Ag nanoparticle. Such localized Au deposition was not observed in the $\mathrm{Au} / \mathrm{TiO}_{2}$ sample. It is an important result to study the heterogeneous catalytic reaction, which is achieved only by HAADF-STEM tomography. In TABLE 1, the 3D morphologies of Au and Ag nanoparticles are summarized.

\section{References}

[1] S.P. Ahrenkiel et al., J. Electron. Microsc. 230 (2008) 382.

[2] K. Kaneko et al., Material Sci. Eng. A 403 (2005) 32.

[3] K. Yoshida et al., J. Appl. Phys. 99 (8) (2006) 084908.

[4] J.C. Gonzales et al., Angew. Chem. 48 (2009) 5313.

[5] A.B. Hungria et al., Catal. Today 143 (2009) 225.

[6] Y. Chen et al., Langmuir, 22 (2006) 2851.
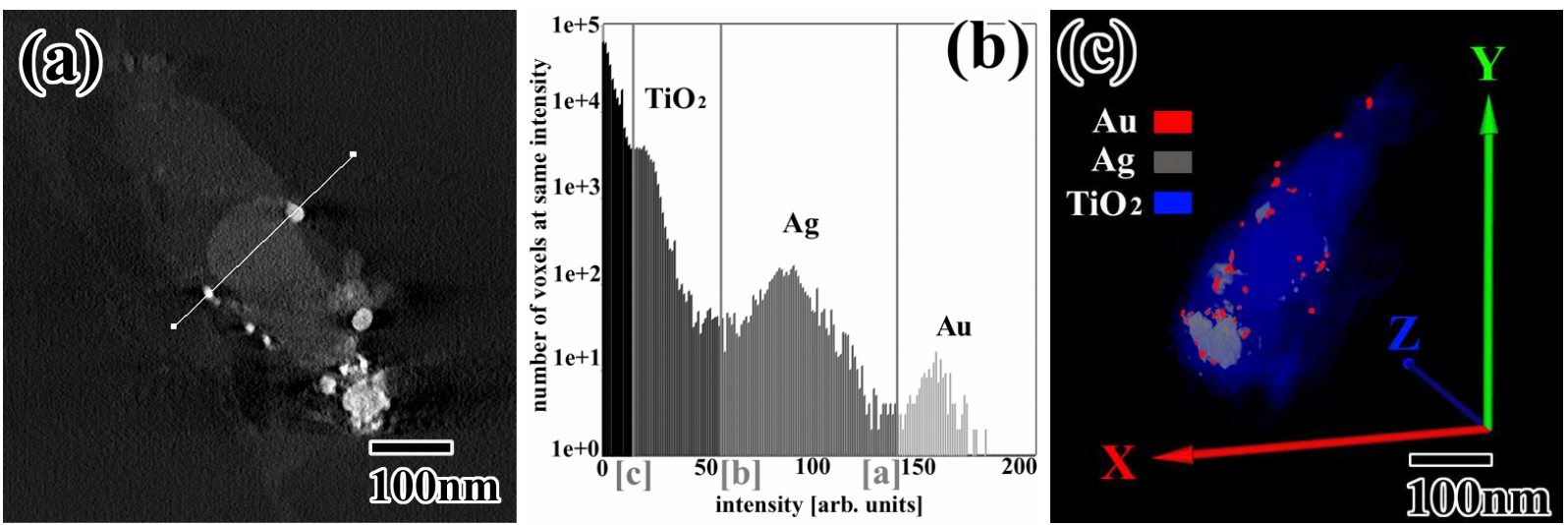

FIG. 1. (a) Z-slice image of $\mathrm{Au} / \mathrm{Ag} / \mathrm{TiO}_{2}$ obtained by STEM tomography. (b)Histogram at Fig. 8a. Two different high intensities show that Au and Ag can be discriminated by STEM tomography. Determining three threshold values between $\mathrm{Au}$ and $\mathrm{Ag}, \mathrm{Ag}$ and $\mathrm{TiO}_{2}, \mathrm{TiO}_{2}$ and vacuum, 3D morphologies can be measured by the TCC method. (c)Colour coded tomogram using multiple threshold values.

TABLE 1. 3D morphologies about $\mathrm{Au} / \mathrm{Ag} / \mathrm{TiO}_{2}$ obtained by the TCC method.

\begin{tabular}{lccccc}
\hline & $\begin{array}{c}\text { total volume } \\
{\left[\mathrm{nm}^{3}\right]}\end{array}$ & $\begin{array}{c}\text { total surface } \\
\text { area }\left[\mathrm{nm}^{2}\right]\end{array}$ & $\begin{array}{c}\text { largest } \\
\text { thickness }[\mathrm{nm}]\end{array}$ & $\begin{array}{c}\text { average nearest- } \\
\text { neighbour distance }[\mathrm{nm}]\end{array}$ & $\begin{array}{c}\text { average particle } \\
\text { volume }\left[\mathrm{nm}^{3}\right]\end{array}$ \\
\hline $\mathrm{Au}$ & $6.5 \times 10^{5}$ & $1.4 \times 10^{5}$ & 77 & 108 & $9.2 \times 10^{3}$ \\
$\mathrm{TiO}_{2}$ & $1.3 \times 10^{8}$ & $1.9 \times 10^{7}$ & 650 & - & \\
\hline
\end{tabular}

